\title{
Recurrent Malignant Female Reproductive System Neoplasm
}

National Cancer Institute

\section{Source}

National Cancer Institute. Recurrent Malignant Female Reproductive System Neoplasm. NCI Thesaurus. Code C150526.

The reemergence of a malignant female reproductive system neoplasm after a period of remission. 